\title{
The Short French Internet Addiction Test adapted to online sexual activities: Validation and links with online sexual preferences and addiction symptoms
}

ARTICLE in THE JOURNAL OF SEX RESEARCH · MAY 2015

Impact Factor: 2.53

DOWNLOADS

50
VIEWS

22

4 AUTHORS, INCLUDING:

Aline Wéry

Catholic University of Louvain

6 PUBLICATIONS 11 CITATIONS

SEE PROFILE

Joel Billieux

Catholic University of Louvain 85 PUBLICATIONS 779 CITATIONS SEE PROFILE

\section{Jonathan Burnay}

University of Liège

3 PUBLICATIONS 1 CITATION

SEE PROFILE 


\title{
The Short French Internet Addiction Test Adapted to Online Sexual Activities: Validation and Links With Online Sexual Preferences and Addiction Symptoms
}

\author{
Aline Wéry ${ }^{\mathrm{a}}$, Jonathan Burnay ${ }^{\mathrm{b}}$, Laurent Karila ${ }^{\mathrm{c}}$, Joël Billieux ${ }^{\mathrm{a}}$
}

Accepted for publication in the Journal of Sex Research in May 2015

${ }^{\text {a} L a b o r a t o r y ~ f o r ~ E x p e r i m e n t a l ~ P s y c h o p a t h o l o g y, ~ P s y c h o l o g i c a l ~ S c i e n c e s ~ R e s e a r c h ~ I n s t i t u t e, ~ U n i v e r s i t e ́ ~}$ Catholique de Louvain, Louvain-la-Neuve, Belgium

${ }^{\mathrm{b}}$ Department of Psychology: Cognition and Behavior, University of Liège, Liège, Belgium ${ }^{\mathrm{c}}$ Addiction Research and Treatment Center, Paul Brousse Hospital, Paris Sud-11 University, AP-HP, INSERM-CEA U1000, Villejuif, France

\section{Corresponding author:}

\author{
Aline Wéry \\ Laboratory for Experimental Psychopathology \\ Psychological Sciences Research Institutes \\ Université Catholique de Louvain \\ Place du Cardinal Mercier, 10 \\ B - 1348 Louvain-la-Neuve, Belgium \\ Phone : + $32(0) 10474546$ \\ E-Mail : aline.wery@uclouvain.be
}




\begin{abstract}
The goal of this study was to investigate the psychometric properties of a French version of the short Internet Addiction Test adapted to online sexual activities (s-IAT-sex). The French version of the s-IAT-sex was administered to a sample of 401 men. The participants also completed a questionnaire that screened for sexual addiction (PATHOS). The relationships of s-IAT-sex scores with time spent online for online sexual activities (OSAs) and the types of OSAs favored were also considered. Confirmatory analyses supported a 2-factor model of the s-IAT-sex, corresponding to the factorial structure found in earlier studies that used the short IAT. The first factor regroups loss of control and time management, whereas the second factor regroups craving and social problems. Internal consistency for each factor was evaluated with Cronbach's $\alpha$ coefficient, resulting in .87 for Factor 1, .76 for Factor 2, and .88 for the global scale. Concurrent validity was supported by relationships with symptoms of sexual addiction, types of OSAs practiced, and time spent online for OSAs. The prevalence of sexual addiction (measured by PATHOS) was $28.1 \%$ in the current sample of self-selected male OSA users. The French version of the s-IAT-sex presents good psychometric properties and constitutes a useful tool for researchers and practitioners.
\end{abstract}

Keywords: Internet Addiction Test, questionnaire validity, factor analysis, online sexual activity, cyberaddiction 
Nowadays, the Internet is an accessible medium that people find helpful in daily life (e.g., for information retrieval, contact with friends or family, or academic and professional activities). Many people are also using the Internet for online sexual activities (OSAs). OSAs are defined by Cooper, Griffin-Shelley, Delmonico, and Mathy (2001) as the use of the Internet (via text, audio, video, and graphic files) for any activity that involves human sexuality, including — but not limited to — having sexual chats, looking for or participating in sex webcams, watching pornography, or seeking off-line sexual partners. In 1998, Cooper postulated that the accessibility (millions of sites accessible 24 hours a day, 7 days a week), affordability (free or low prices on adult sites), and perceived anonymity (the online user is not physically seen and may consider him- or herself to be undetectable to others) of the Internet provides a convenient medium for sexual behaviors.

In most cases, these OSAs have no negative impact on daily living (Albright, 2008; Ballester-Arnal, Castro-Calvo, Gil-Llario, \& Giménez-García, 2014). Nevertheless, for a subgroup of individuals, OSAs can become excessive and affect several facets of their lives (Cooper, Delmonico, Griffin-Shelley, \& Mathy, 2004; Grov, Gillespie, Royce, \& Lever, 2011; Philaretou, Ma Ihfouz, \& Allen, 2005). Problematic OSA is characterized by repetition of excessive use of online sexual activities; loss of control; persistent desire or unsuccessful efforts to stop, reduce, or control OSAs behaviors; withdrawal (negative mood states when OSAs are unavailable); tolerance (need for more hours of use or more new sexual content); and negative consequences (Block, 2008; Carnes, 2000).

To date, evidence regarding the prevalence of problematic OSA is scarce. In 2002, Cooper, Morahan-Martin, Mathy, and Maheu found a 9.6\% prevalence of problematic OSA, whereas in 2006 Daneback, Ross, and Månsson found a prevalence of 6\%. More recently, a study conducted by Ross, Månsson, and Daneback (2012) reported a 5\% prevalence of problematic OSA in women and $13 \%$ in men. Nonetheless, the diagnosis criteria and the 
THE S-IAT-SEX: VALIDATION AND LINKS WITH ONLINE SEXUAL PREFERENCES AND

ADDICTION SYMPTOMS

instruments used have varied considerably in published studies, making a comparison of the results tentative (Karila et al., 2014; Wéry, Karila, De Sutter, \& Billieux, 2014).

Indeed, despite the increase in studies on Internet-related disorders and, to a lesser extent, problematic OSA, the diagnostic criteria are still under debate and assessment tools are highly heterogeneous (in terms of both symptom coverage and psychometric quality;

Griffiths, King, \& Demetrovics, 2014; Kuss, Griffiths, Karila, \& Billieux, 2014). Several screening instruments have been developed to assess Internet-related disorders, but the Internet Addiction Test (IAT; Young, 1998) is one of the most frequently used. The IAT consists of 20 items that measure the symptoms associated with excessive use of the Internet (e.g., preoccupation with the Internet, increased anxiety when off-line, impairment in real-life functioning; see Young, Pistner, O’Mara, \& Buchanan, 1999).

Despite the wide adoption of the scale, however, its psychometric properties are still debated, particularly because the studies testing its factorial structure and validity are limited and have obtained mixed results (Faraci, Craparo, Messina, \& Severino, 2013; Pawlikowski, Altstötter-Gleich, \& Brand, 2013). On the whole, existing validation studies performed on the IAT showed a six-factor solution (Widyanto \& McMurran, 2004), a three-factor solution (Chang \& Law, 2008), a two-factor solution (Barke, Nyenhuis, \& Kröner-Herwig, 2012; Faraci, Craparo, Messina, \& Severino, 2013; Jelenchick, Becker, \& Moreno, 2012; Korkeila, Kaarlas, Jääskeläinen, Vahlberg, \& Taiminen, 2010; Watters, Keefer, Kloosterman, Summerfeldt, \& Parker, 2013), or a one-factor solution (Faraci et al., 2013; Khazaal et al., 2008; Korkeila, Kaarlas, Jääskeläinen, Vahlberg, \& Taiminen, 2010). The heterogeneity of these results can be attributed to the fact that many studies used this scale in various settings with a diversity of participants (e.g., different ages, nationalities; Faraci et al., 2013). Moreover, some studies relied only on exploratory factor analyses (EFAs), whereas others used a combination of EFA and confirmatory factor analysis (CFA). In addition, different 
THE S-IAT-SEX: VALIDATION AND LINKS WITH ONLINE SEXUAL PREFERENCES AND

ADDICTION SYMPTOMS

researchers used different item-reduction techniques when conducting factor analyses, which influenced the number of factors extracted and had a negative impact on the generalization of these findings (Watters et al., 2013).

Faced with the "psychometrical chaos" and inconsistent results among existing studies, Pawlikowski et al. (2013) recently developed a short version of the IAT (s-IAT). Items with low factor loadings $(<.50)$ and/or high loadings on more than one factor $(>.20)$ were removed from the original scale (i.e., Items 4, 5, 7, 10, 11, and 12). Two supplementary items (Items 8 and 3) were excluded because of content overlap with items that had higher loadings. Pawlikowski et al. (2013) also justified the removal of several items because they were outdated and needed to be updated (e.g., Item 7 refers to checking email, but communication has now extended to other applications such as Facebook or Skype). After excluding the aforementioned items, the researchers retained 12 items drawn from the 20 -item version of the IAT. The factorial structure of the short IAT (s-IAT) was established by using a combination of EFA and CFA on two independent samples, which validated a two-factor model. The two factors were labeled "loss of control/time management" (six items) and “craving/social problems" (six items).

Another limitation of the original IAT is that it does not take into account the type of online activity practiced. Accordingly, encouragement has grown in recent years for the development of screening questionnaires that target specific forms of Internet usage (e.g., OSAs or online games) (Kuss et al., 2014; Pawlikowski et al., 2013; Starcevic, 2013). In this vein, the original (20-item) version of the IAT has recently been adapted to evaluate addiction to online role-playing games (Billieux, Thorens, Khazaal., Zullino, Achab, \& Van der Linden, 2015; Chan \& Rabinowitz, 2006; Pawlikowski \& Brand, 2011) and to online sexual activities (Brand, Laier, Pawlikowski, Schachtle, Scholer, \& Altstotter-Gleich, 2011). Interestingly, Laier and colleagues conducted several studies by using a German version of 
the s-IAT specifically adapted to assess problematic involvement in OSA (s-IAT-sex; see Laier \& Brand, 2014; Laier, Pawlikowski, Pekal, Schulte, \& Brand, 2013; Laier, Pekal, \& Brand, 2014). The German s-IAT-sex was found to have good overall internal consistency, with a Cronbach's $\alpha$ coefficient of between .84 and .91 (Laier et al., 2013, 2014). However, the factorial structure of the s-IAT-sex remains unexplored, even though Laier and Brand (2014) relied on the two-factor model established for the s-IAT by Pawlikowski et al. (2013). The goal of the present paper was to investigate the psychometric properties of a French version of the s-IAT adapted to OSAs (s-IAT-sex; 12 items) in a sample of men. The study focused on males because the prevalence of sexual addiction is higher in men than in women, the estimated ratio of sexual addiction being between 3 and 5 men to each woman (Black, Kehrberg, Flumerfelt, \& Schlosser, 1997; Carnes, 2000). More specifically, the aims of the current investigation were (a) to establish the factor structure of the s-IAT-sex by using CFA and (b) to test the concurrent validity of the scale through consideration of the relationship between Internet sexual use and time spent online, the types of OSAs practiced, and symptoms of sexual addiction (not related to the Internet per se; Carnes, Green, Merlo, Polles, Carnes, \& Gold, 2012).

\section{Method}

\section{Participants and Procedure}

The study consisted of a survey that was accessible online and was circulated on a university messaging service, social networks, research networks, and sexuality-related forums. Inclusion criteria were French-speaking men who were aged 18 years and older. All participants were informed about the study and gave online consent before starting the online survey. Anonymity of the participants was guaranteed (no personal data or Internet Protocol [IP] address was collected). No compensation was given for participating in the study. The 
THE S-IAT-SEX: VALIDATION AND LINKS WITH ONLINE SEXUAL PREFERENCES AND ADDICTION SYMPTOMS

ethical committee of the Psychological Sciences Research Institute, Catholic University of Louvain, approved the study protocol. A total of 401 men who used OSAs participated in the study. Some questionnaires included in the survey did not relate to the current study and will be presented elsewhere. All participants included in the current study completed the French version of the s-IAT-sex in its entirety.

The participants answered sociodemographic questions about age, nationality, education, occupation, sexual orientation, and relationship status. The mean age of the participants was 28.74 years $(S D=8.80$, range $18-72$ years). Most respondents had a bachelor's or master's degree (82.8\%), and most were active workers $(43.5 \%)$ or students $(49.3 \%)$. Sixty percent were in a relationship, and most were heterosexual (88.5\%). In addition, the participants estimated their weekly OSAs time ( $n=394$ due to missing data). The mean frequency of weekly OSAs use was $3 \mathrm{hr}(S D=4.62 \mathrm{hr}$, range $5 \mathrm{~min}$ to $33 \mathrm{hr}$; see Table 1).

They also evaluated their OSAs on a 5-point Likert scale ranging from 1 (never) to 5 (very often) ( $n=388$ due to missing data). The following sexual-related online activities were reported (i.e., if participants answered being at least "rarely" involved in a specific OSA during the last 3 months): $99.2 \%$ of the sample viewed pornographic pictures or films, $68 \%$ searched for sex-related information, $65.2 \%$ read online advice regarding sexual practices, 37.4\% read pornographic literature, $31.7 \%$ looked for love contacts, $25.5 \%$ looked for off-line sexual contacts, $24.7 \%$ watched live sex shows via webcam, $24.2 \%$ engaged in sex chats, 22.2\% looked for online sexual contacts, $19.3 \%$ engaged in sex via webcam, $18 \%$ used online sex shops, and $4.1 \%$ contacted prostitutes/sex workers. In addition, the participants completed the PATHOS (Carnes et al., 2012), a brief instrument that measures sexual addiction $(n=363$ due to missing data). 


\section{Insert Table 1}

\section{Instruments}

s-IAT-sex. The s-IAT-sex is a 12 -item scale used to assess subjective complaints in everyday life due to OSAs and potential symptoms of problematic OSA (see Appendices A and B for the French items and the corresponding English items). To create a French version of the s-IAT-sex, we applied a translation and back-translation procedure to 12 items of the modified version of the IAT (IAT-sex) by Brand et al. (2011), and Laier et al. (2013). The 12 items retained were based on the s-IAT developed by Pawlikowski et al. (2013). The terms "online" or "Internet" were thus systematically replaced by the terms "online sexual activity" and "Internet sex sites," respectively. All items were scored on a Likert scale (never, rarely, occasionally, often, always) corresponding to scores of 1 to 5 .

PATHOS. PATHOS (Carnes et al., 2012) is a brief instrument to screen for sexual addiction that consists of six dichotomous items. Each item assesses different criteria: (a) preoccupied with sexual thoughts, (b) feel ashamed, (c) treatment seeking, (d) hurt others because of the sexual behavior, (e) loss of control, and (f) feeling depressed after engaging in sexual behaviors. All items are scored in a yes/no format, the total score being 6 with a cutoff of 3 (Carnes et al., 2012). The French version of the scale was developed as follows: (a) The third author of the article, with the help of an English-French bilingual translator, translated the six items of the original PATHOS into French; (b) another English-French bilingual translator translated the French version back into English; and (c) all discrepancies identified between the original PATHOS and the back-translation were discussed until a satisfactory solution was found. In the current study, the mean PATHOS score was $1.89(S D=1.45)$. Using the cutoff score of 3 proposed by Carnes et al. (2012), we categorized $71.6 \%$ of the 
THE S-IAT-SEX: VALIDATION AND LINKS WITH ONLINE SEXUAL PREFERENCES AND

ADDICTION SYMPTOMS

sample $(n=260)$ as healthy subjects (score $<3)$, and $28.4 \%$ of the sample $(n=103)$ as having addictive sexual behaviors ( score $\geq 3$ ).

\section{Statistical Analyses}

To determine the factor structure of the French s-IAT-sex, we analyzed the covariance matrix with a confirmatory analysis computed with LISREL 8.8 (Jöreskog \& Sörbom, 1996). Drawing upon the existing literature, we computed two different models: A one-factor model, as the IAT was originally developed as a single-scale instrument (Watters et al., 2013), and a two-factor model inspired by the validation of the s-IAT (Pawlikowski et al., 2013). According to Pawlikowski et al. (2013), the two extracted factors correspond to "loss of control/time management" and "craving/social problems." Goodness of fit was tested with $\chi^{2}$ (a nonsignificant value corresponds to an acceptable fit). However, $\chi^{2}$ is known to increase with sample size, and Byrne (1994) has noticed that it is unusual to obtain a nonsignificant $\chi^{2}$ when performing CFAs on self-report questionnaires. We therefore performed the $\chi^{2}$ test by examining other indices that depend on conventional cutoffs: root mean square error of approximation (RMSEA), Comparative Fit Index (CFI), Adjusted Goodness of Fit Index (AGFI), Normed Fit Index (NFI), and Non-Normed Fit Index (NNFI). A RMSEA < .08, a $\mathrm{CFI}>.95$, an AGFI $>.85$, an NFI $>.90$ and an NNFI $>.95$ are generally interpreted as an acceptable fit. Moreover, the chi-square difference test was used to compare the models. Internal consistency was calculated with Cronbach's $\alpha$ (Brown, 2006). Pearson's correlations were then conducted to evaluate the relationship between the score on the s-IAT-sex and time spent online per week for OSAs, as well as between the score on the s-IAT-sex and that on the PATHOS. Pearson's correlation was also used to evaluate the effect of OSAs on the score for the s-IAT-sex. According to Cohen (1988), a correlation between 0.10 and 0.30 corresponds to a small effect, between 0.30 and 0.50 to a medium effect, and above 0.50 to a large effect. Correlations were calculated with $95 \%$ confidence intervals. 


\title{
Results
}

\section{Confirmatory Factor Analysis (CFA)}

A Skewness and Kurtosis test indicated that multivariate normality was not respected $(\mathrm{p}<.001)$. Consequently, all CFAs analyses were computed using a Diagonally Weighted Least Square method of estimation suited for non-normal data.

CFA was computed on the 12 items of the s-IAT-sex. Two models were tested: a onefactor model and a two-factor model. The covariance matrix between all items is provided in Table 2. The one-factor model has a poor fit (Model 1, Table 3), $\chi^{2}(54)=267.335, p<.001$; $\mathrm{RMSEA}=.0994 ; \mathrm{CFI}=.955 ; \mathrm{AGFI}=.968 ; \mathrm{NFI}=.945 ; \mathrm{NNFI}=.945$. To define a model with two dimensions, we allowed the latent variables to correlate. The following causality relations were calculated: (a) The latent variable "loss of control/time management" is explained by Items $1,2,3,6,8$, and 9; and (b) the latent variable "craving/social problems" is explained by Items 4, 5, 7, 10, 11, and 12. The two-factor model has an acceptable fit (Model 2, Table 3), $\chi^{2}(53)=184.421, p<.001 ; \mathrm{RMSEA}=.0787 ; \mathrm{CFI}=.972 ; \mathrm{AGFI}=.976 ; \mathrm{NFI}=.962 ; \mathrm{NNFI}=$ .966.

In addition to the fit indices, the chi-square difference test for nested models (Brown, 2006) showed that the two-factor model (Model 2) is superior to the one-factor model (Model $\left.1 ; \chi_{\text {diff }}^{2}=82.914, d f_{\text {diff }}=1, p<.001\right)$.

\author{
Insert Table 2 \\ Insert Table 3 \\ Insert Figure 1
}




\section{Descriptive Statistics, Internal Consistency, Reliability, and Correlation Among All Facets of the s-IAT-sex}

Descriptive results and intercorrelations between the s-IAT-sex factors are reported on Table 4. Internal consistency for each factor was evaluated with Cronbach's $\alpha$ coefficient, resulting in 87 for Factor 1, .76 for Factor 2, and .88 for the global scale. These values correspond to good internal consistency. The correlation between the two facets of the s-IATsex is equal to $.66(p<.01)$. In the current study, the mean s-IAT-sex score (12 items) was $22.11(S D=8.95$, range $12-59)$.

\section{Insert Table 4}

\section{Centiles for the Total Score and the Subscales of the s-IAT-sex}

Table 5 presents the centiles (the values of a variable below which a certain percentage of observations fall) of the overall and subscale scores of the s-IAT-sex. The results suggested that these score distributions are relatively symmetrical, supporting the idea that these scores correctly discriminate individuals.

\section{Insert Table 5}

\section{Correlations Between the s-IAT-sex and Other Measures (Time Online, OSAs, and PATHOS)}

Table 6 reports Pearson's correlations between the s-IAT-sex scores and time spent online for OSAs and between the s-IAT-sex scores and PATHOS; Table 7 reports Pearson's correlations between the s-IAT-sex scores and involvement in OSAs. Correlation analyses revealed positive significant relationships (a) between s-IAT-sex scores and time spent online for OSAs weekly, (b) between s-IAT-sex scores and PATHOS global scores, and (c) between 
s-IAT-sex scores and all OSAs (except for "using online sex shops" and "searching for sexrelated information"). Nevertheless, using pornography, engaging in sex chats, and using sex webcam were the activities that correlated most with a high s-IAT-sex score. Interestingly, Factor 1 (loss of control/time management) correlates more strongly with partner-arousal OSAs. This dissociation is more marked with OSAs related to searching for off-line and online sexual contacts (see Table 7).

Insert Table 6

Insert Table 7

\section{Discussion}

The goal of the current study was to establish the factorial structure of the s-IAT adapted to OSAs and to explore its relations with sexual addiction and types of OSAs practiced in a sample of French-speaking men. After we removed one problematic item, the CFAs showed that a two-factor model fits the data well, resulting in psychometrically sound scales characterized by good internal reliability. The two-factor structure evidenced in the current study corresponds to that previously found by Pawlikowski et al. (2013) with the original German s-IAT. The first factor corresponds to "loss of control/time management" (Items 1, 2, 3, 6, 8, and 9). The items of this subscale assess symptoms involving the failure to control or reduce the amount of time spent online for OSAs. The second factor corresponds to “craving/social problems" (Items 4, 5, 7, 10, 11, 12). The items of this subscale measure functional impairment associated with OSAs use (including irritation, craving and preoccupation, social impact, and mood regulation).

This study also tested how the various dimensions of the s-IAT-sex relate to actual online sexual behaviors and symptoms of sexual addiction. A significant positive correlation was found between s-IAT-sex scores and time spent online for OSAs. Similar results have 
been described in other studies (Cooper et al., 2001; Wetterneck, Burgess, Short, Smith, \& Cervantes, 2012), although not consistently (Brand et al., 2011). In addition, we found a significant positive correlation between s-IAT-sex scores and almost every type of OSA (except for "using online sex shops" and "searching for sex-related information"), but especially between the s-IAT-sex score and watching pornography, using sex chats, and using sex webcam. These findings are partly consistent with those from a Swedish study by Ross et al. (2012), in which the investigators reported pornography to be the OSA that correlated most with problematic OSA. Interestingly, we also found that partner-arousal OSAs (e.g., looking for off-line/online sexual contacts) presented higher correlations with Factor 1 than did solitary-arousal OSAs (e.g., watching pornography). A possible explanation is that partnerarousal OSAs are interpersonal behaviors (e.g., sexual games or rituals, striptease) involving the commitment of two or more individuals, which generally last longer than the compulsive search for pleasure or relief that characterizes solitary-arousal OSAs. Finally, a significant positive correlation was found in our study between s-IAT-sex scores and sexual addiction (PATHOS). Moreover, the correlations between the six items of PATHOS and the two factors of the s-IAT-sex supported convergent validity.

The current study adds to the literature by providing a psychometrically sound scale to assess problematic involvement in OSAs in the French language. This is important, as an improvement in the screening instruments for Internet-related disorders is required. For example, most previous studies have been conducted by relying only on EFAs, which brings into question the generalizability of the findings. Another strength of the current study is that it supports the validity of an instrument devoted to the assessment of a specific problematic OSA. This assessment is in accordance with a recent proposal stipulating that disentangling the various problematic behaviors incorporated in the umbrella construct of "Internet addiction" is prerequisite for reducing the conceptual chaos that characterizes this research 
field (Kuss et al., 2014). It is worth noting that the s-IAT-sex is particularly adapted to screening for problematic OSA in the clinical context in which time-consuming questionnaires are generally banned.

Nonetheless, several limitations exist in this study. First, all of the measures were selfreport questionnaires that presume respondents are aware of and willing to report their sexual attitudes and sexual behaviors honestly. Second, the online survey method implies that the sample is self-selected, which influences its representativeness (Khazaal et al., 2014). In our study, for example, we found a prevalence rate for sexual addiction of $28.1 \%$, which is very high. However, it is likely that this elevated prevalence rate is at least partly explained by the fact that our study attracted individuals who felt concerned by OSAs. Third, to maintain the anonymity of the respondents, the IP addresses were not recorded. Indeed, online studies allow the collection of more respondents through the anonymity offered by the Internet, and this is especially true when using a questionnaire for stigmatized behaviors such as sexual practices. In their free comments, several respondents indicated that the anonymity of the online method encouraged honest answers. Nevertheless, we cannot formally exclude the possibility that some participants filled out the questionnaire several times, although they would gain no advantage by doing so. Fourth, our sample is composed of males only, implying that the psychometric properties of the s-IAT-sex must be confirmed in a sample that includes females. Indeed, the only previous study that used the s-IAT-sex for females (Laier et al., 2014) did not investigate its factorial structure, although previous studies found that women tend to be interested in interactive OSAs (e.g., sexual chat), whereas men tend to be interested in visual OSAs (e.g., pornography; Cooper, Månsson, Daneback, Tikkanen, \& Ross, 2003; Green, Carnes, Carnes, \& Weinman, 2012). Although we showed that the twofactor model is clearly superior to the one-factor model, the correlation between the factors is elevated and the two factors failed to clearly distinguish between the types of OSA practiced 
THE S-IAT-SEX: VALIDATION AND LINKS WITH ONLINE SEXUAL PREFERENCES AND ADDICTION SYMPTOMS

(except for partner-arousal activities, which correlated more with the loss of control/time management factor) or the presence of sexual addiction symptoms. Moreover, despite the fit indices of the CFA indicate an acceptable model, the chi-squared test was significant, implying that the model does not fit the data to at least some degree. Further studies are thus required to reinforce the validity of the factorial structure of the French s-IAT-sex. In particular, future studies should (1) refine the wording of some items to reduce content overlap and (2) test the specific association between the factors of the s-IAT-sex and other factors that have been associated with OSAs, such as personality traits (e.g., impulsivity) or the individual motives that support involvement in OSAs (Griffiths, 2012).

Despite these limitations, the current study showed that the French version of the sIAT-sex is a promising instrument for assessing problematic OSA in both research and clinical practice. Indeed, one of the most important aspects of short-form development is the trade-off between reduction of assessment time and loss of validity (Smith, McCarthy, \& Anderson, 2000). In the current study, we found the French s-IAT-sex to have acceptable factorial structure. Moreover, concurrent validity of the scale was supported by relationships with symptoms of sexual addiction, types of OSAs practiced, and time spent online for OSAs. Eventually, the internal reliability coefficient of the s-IAT-sex is near to those obtained with the original French IAT (Khazaal et al., 2008) and the original IAT-sex (Brand et al., 2011). Indeed, Cronbach's $\alpha$ coefficient for the whole scale was .88 for the French s-IAT-sex, .93 for the French IAT, and .84 for the IAT-sex. Taken together, these results support the use of the French s-IAT-sex for meaningful time-saving. Importantly, this study also confirms that disentangling online activities is required to improve the quality of Internet-disorders screening instruments. 
THE S-IAT-SEX: VALIDATION AND LINKS WITH ONLINE SEXUAL PREFERENCES AND ADDICTION SYMPTOMS

\section{Acknowledgments}

The authors thank Matthias Brand for his generous authorization of the validation of the sIAT-sex into the French language, and Patrick Carnes for his permission to translate PATHOS into a French version and to test it.

\section{Disclosure Statement}

Joël Billieux is funded by the European Commission for research on the problematic sage of information and communication technology ("Tech Use Disorders"; Grant ID: FP7-PEOPLE2013-IEF-627999). This funding body did not exert any editorial direction or censorship on any part of this article. 
THE S-IAT-SEX: VALIDATION AND LINKS WITH ONLINE SEXUAL PREFERENCES AND ADDICTION SYMPTOMS

\section{Table 1}

Participants' Characteristics

\begin{tabular}{|c|c|c|}
\hline Characteristics & $N$ valid & $M(S D)$ or $\%$ \\
\hline Age & 401 & $28.74(8.80)$ \\
\hline Nationality & 401 & \\
\hline Belgian & & $44.6 \%$ \\
\hline French & & $34.7 \%$ \\
\hline Canadian & & $17 \%$ \\
\hline Swiss & & $1 \%$ \\
\hline Other European country & & $1.2 \%$ \\
\hline Other non-European country & & $1.5 \%$ \\
\hline Level of education & 401 & \\
\hline Primary school & & $1 \%$ \\
\hline College & & $14.2 \%$ \\
\hline High school & & $23.3 \%$ \\
\hline University & & $59.9 \%$ \\
\hline Other & & $1.5 \%$ \\
\hline Sexual orientation & 401 & \\
\hline Heterosexual & & $88.5 \%$ \\
\hline Homosexual & & $9.2 \%$ \\
\hline Bisexual & & $2.2 \%$ \\
\hline Relationship status & 401 & \\
\hline Never in a relationship & & $4 \%$ \\
\hline Single (without occasional sexual partner) & & $19.2 \%$ \\
\hline Single (with occasional sexual partner(s)) & & $16.7 \%$ \\
\hline In a stable relationship for less than a year & & $15.7 \%$ \\
\hline In a stable relationship for more than a year & & $44.4 \%$ \\
\hline Frequency of weekly OSAs use & 394 & $3 \mathrm{hr}(4.62 \mathrm{hr})$ \\
\hline
\end{tabular}


THE S-IAT-SEX: VALIDATION AND LINKS WITH ONLINE SEXUAL PREFERENCES AND ADDICTION SYMPTOMS

\section{Table 2}

Descriptive Statistics and Covariance Matrix of All Items

\begin{tabular}{llllllllllllllll}
\hline & $M$ & $S D$ & Q1 & Q2 & Q3 & Q4 & Q5 & Q6 & Q7 & Q8 & Q9 & Q10 & Q11 & Q12 \\
\hline Q1 & 2.97 & 1.29 & 1.677 & - & - & - & - & - & - & - & - & - & - & - \\
Q2 & 1.95 & 1.23 & 0.996 & 1.523 & - & - & - & - & - & - & - & - & - & - \\
Q3 & 1.43 & 0.90 & 0.442 & 0.724 & 0.815 & - & - & - & - & - & - & - & & \\
Q4 & 1.91 & 1.18 & 0.305 & 0.410 & 0.297 & 1.404 & - & - & - & - & - & - & - & - \\
Q5 & 1.54 & 0.97 & 0.287 & 0.347 & 0.258 & 0.415 & 0.949 & - & - & - & - & - & - & - \\
Q6 & 1.65 & 1.05 & 0.650 & 0.853 & 0.469 & 0.298 & 0.325 & 1.108 & - & - & - & - & - & - \\
Q7 & 1.72 & 0.93 & 0.425 & 0.518 & 0.344 & 0.209 & 0.282 & 0.475 & 0.869 & - & - & - & - & - \\
Q8 & 2.00 & 1.29 & 1.080 & 0.885 & 0.476 & 0.280 & 0.231 & 0.704 & 0.477 & 1.657 & - & - & - & - \\
Q9 & 1.74 & 1.22 & 0.700 & 0.830 & 0.506 & 0.379 & 0.269 & 0.624 & 0.464 & 0.754 & 1.478 & - & - & - \\
Q10 & 2.53 & 1.55 & 0.639 & 0.686 & 0.390 & 0.746 & 0.331 & 0.644 & 0.510 & 0.641 & 0.789 & 2.410 & - & - \\
Q11 & 1.32 & 0.83 & 0.454 & 0.651 & 0.404 & 0.315 & 0.331 & 0.498 & 0.380 & 0.486 & 0.457 & 0.496 & 0.690 & - \\
Q12 & 1.36 & 0.85 & 0.360 & 0.553 & 0.421 & 0.281 & 0.354 & 0.431 & 0.405 & 0.401 & 0.453 & 0.466 & 0.503 & 0.716 \\
\hline
\end{tabular}


THE S-IAT-SEX: VALIDATION AND LINKS WITH ONLINE SEXUAL PREFERENCES AND ADDICTION SYMPTOMS

\section{Table 3}

Fit Indices of the Confirmatory Factor Analysis

\begin{tabular}{llllll}
\hline Model & $\chi^{2}$ & $d f$ & $\mathrm{~N}$ & RMSEA (90\% CI) & CFI \\
\hline Model 1 & 267.335 & 54 & 401 & $.0994[.0877, .111]$ & .955 \\
Model 2 & 184.421 & 53 & 401 & $.0787[.0665, .0913]$ & .972 \\
\hline
\end{tabular}

Note. RMSEA = root mean square error of approximation; $\mathrm{CI}=$ confidence interval; $\mathrm{CFI}=$ Comparative Fit Index. 


\section{Figure 1}

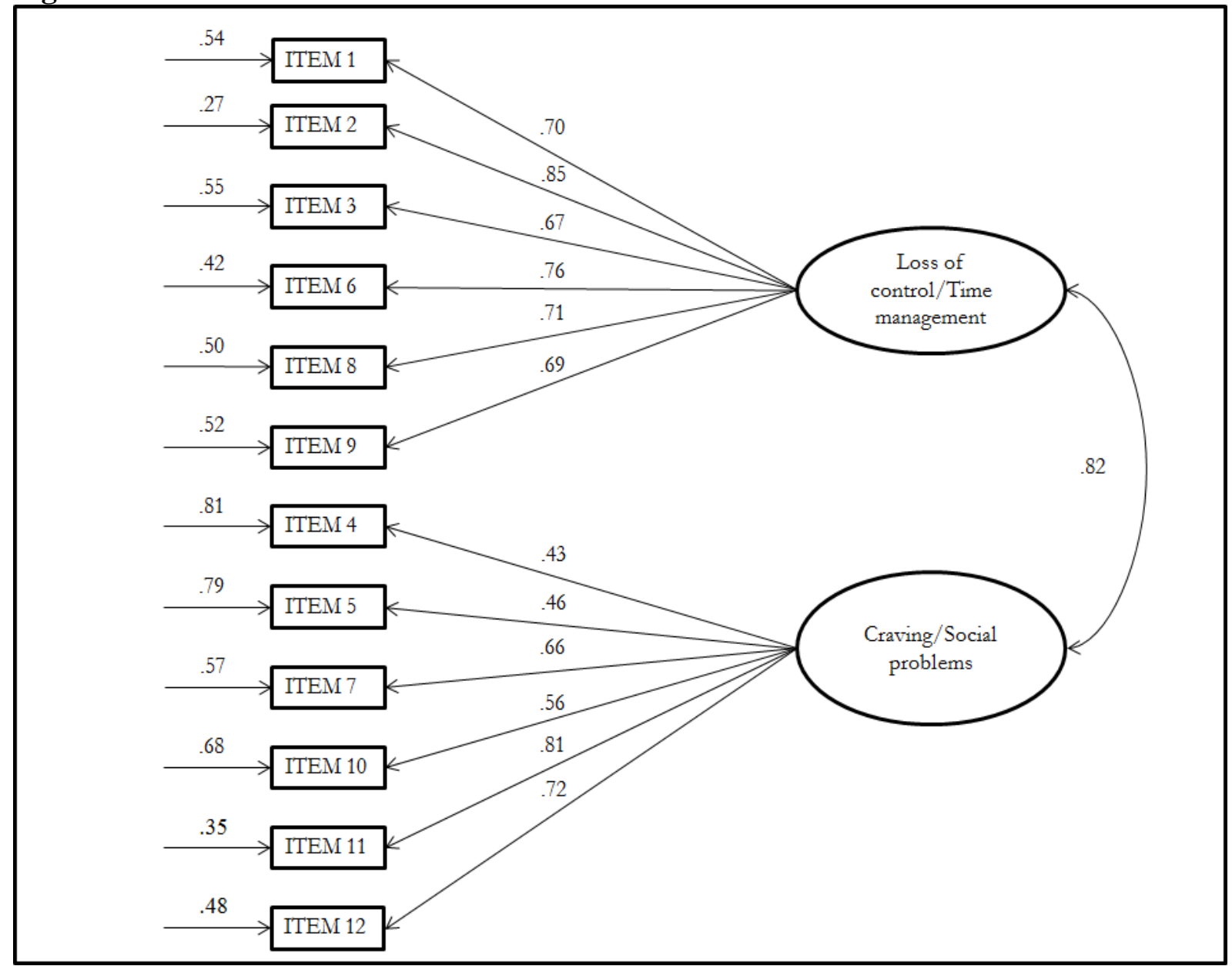

Figure 1. A 12-item two-factor model (Model 2) in which all latent variables are represented

by ovals and all manifest variables are represented by rectangles. Single-headed arrows

represent error variance and standardized factor loading $(\beta)$; the double-headed arrow

represents the correlation between the latent variables. The correlation of .82 between the two factors was calculated by LISREL, which took into account the covariance between each item. 
THE S-IAT-SEX: VALIDATION AND LINKS WITH ONLINE SEXUAL PREFERENCES AND ADDICTION SYMPTOMS

\section{Table 4}

Unstandardized $(\rho)$ and Standardized Coefficients $(\beta)$

\begin{tabular}{|c|c|c|c|c|c|c|c|c|c|c|c|c|}
\hline & \multicolumn{6}{|c|}{ Factor 1} & \multicolumn{6}{|c|}{ Factor 2} \\
\hline & Q1 & Q2 & Q3 & Q6 & Q8 & Q9 & Q4 & Q5 & Q7 & Q10 & Q11 & Q12 \\
\hline$\rho$ & 0.879 & 1.054 & 0.606 & 0.804 & 0.911 & 0.842 & 0.513 & 0.445 & 0.612 & 0.874 & 0.670 & 0.610 \\
\hline$t$ & $19.82 * * *$ & $18.90 * * *$ & $8.19 * * *$ & $12.06^{* * *}$ & $15.97 * * *$ & $11.52 * * *$ & $6.86 * * *$ & $6.28 * * *$ & $10.55 * * *$ & $12.51 * * *$ & $9.21 * * *$ & $8.34 * * *$ \\
\hline$S D$ & 0.90 & 0.41 & 0.45 & 0.46 & 0.83 & 0.77 & 1.14 & 0.75 & 0.49 & 1.65 & 0.24 & 0.34 \\
\hline$\beta$ & .679 & .854 & .672 & .764 & .708 & .693 & .433 & .457 & .657 & .563 & .807 & .721 \\
\hline$S D$ & .54 & .27 & .55 & .42 & .50 & .52 & .81 & .79 & .57 & .68 & .35 & .48 \\
\hline
\end{tabular}

$* * * p<.001$ 
THE S-IAT-SEX: VALIDATION AND LINKS WITH ONLINE SEXUAL PREFERENCES AND ADDICTION SYMPTOMS

\section{Table 5}

Centiles of the Overall s-IAT-sex Scale and Subscale Score Distribution

\section{Centiles}

\begin{tabular}{|c|c|c|c|c|c|c|c|}
\hline s-IAT-sex & 5 th & 10th & 25 th & 50th & 75 th & 90th & 95 th \\
\hline Overall score & 12 & 13 & 16 & 20 & 25 & 36 & 42 \\
\hline Loss of control/Time & 6 & 6 & 7 & 10 & 14 & 21 & 24 \\
\hline management & & & & & & & \\
\hline Craving/Social & 6 & 6 & 7 & 9 & 12 & 16 & 19 \\
\hline
\end{tabular}

Note. s-IAT-sex $=$ short version of the Internet Addiction Test adapted to online sexual activities. 
THE S-IAT-SEX: VALIDATION AND LINKS WITH ONLINE SEXUAL PREFERENCES AND ADDICTION SYMPTOMS

\section{Table 6}

Pearson's Correlations Between External and Convergent Validity Measures and the s-IAT$\operatorname{sex}$

Factors

\section{Loss of control/}

Time Craving/Social

\begin{tabular}{lllll} 
& $N$ valid & s-IAT-sex & management & problems \\
\hline Time spent online & 394 & $.33^{* *}$ & $.32^{* *}$ & $.28^{* *}$ \\
PATHOS & 363 & $.63^{* *}$ & $.62^{* *}$ & $.52^{* *}$
\end{tabular}

Preoccupied with sexual

$.30 * * \quad .41 * *$

$.29 * *$

thoughts

Feel ashamed

$.29 * *$

$.23 * *$

$.30 * *$

Treatment seeking

Hurt others

Loss of control

$.46 * *$

$.48 * *$

$.35^{* *}$

Feeling depressed

$.49 * *$

$.46 * *$

$.44 * *$

Note. s-IAT-sex $=$ short version of the Internet Addiction Test adapted to online sexual activities.

$* * p<.01$. 
THE S-IAT-SEX: VALIDATION AND LINKS WITH ONLINE SEXUAL PREFERENCES AND ADDICTION SYMPTOMS

\section{Table 7}

Pearson's Correlations Between Concurrent Validity Measures and the s-IAT-sex

\begin{tabular}{|c|c|c|c|c|}
\hline & \multirow[b]{3}{*}{$N$ valid } & \multirow[b]{3}{*}{ s-IAT-sex } & \multicolumn{2}{|c|}{ Factors } \\
\hline & & & \multicolumn{2}{|c|}{ Loss of control/ } \\
\hline & & & $\begin{array}{l}\text { Time } \\
\text { management }\end{array}$ & $\begin{array}{l}\text { Craving/Social } \\
\text { problems }\end{array}$ \\
\hline Online sexual activities & 388 & & & \\
\hline $\begin{array}{l}\text { Searching for sex-related } \\
\text { information }\end{array}$ & & .06 & .06 & .05 \\
\hline Reading online advices & & $.19 * *$ & $.19 * *$ & $.15^{* *}$ \\
\hline Looking for love contacts & & $.18^{* *}$ & $.19 * *$ & $.12^{*}$ \\
\hline $\begin{array}{l}\text { Looking for online sexual } \\
\text { contacts }\end{array}$ & & $.31 * *$ & $.35 * *$ & $.20 * *$ \\
\hline $\begin{array}{l}\text { Looking for offline sexual } \\
\text { contacts }\end{array}$ & & $.18^{* *}$ & $.22 * *$ & .08 \\
\hline $\begin{array}{l}\text { Contacting prostitutes/sex } \\
\text { workers }\end{array}$ & & $.17 * *$ & $.16^{* *}$ & $.15^{* *}$ \\
\hline $\begin{array}{l}\text { Watching live sex shows } \\
\text { via webcam }\end{array}$ & & $.27 * *$ & $.29 * *$ & $.20 * *$ \\
\hline $\begin{array}{l}\text { Engaging in sex via } \\
\text { webcam }\end{array}$ & & $.29 * *$ & $.30 * *$ & $.22 * *$ \\
\hline Engaging in sex chats & & $.28 * *$ & $.31 * *$ & $.19 * *$ \\
\hline Using online sex shops & & .06 & .06 & .04 \\
\hline Reading pornographic & & $.12^{*}$ & $.12^{*}$ & .10 \\
\hline literature & & & & \\
\hline $\begin{array}{l}\text { Viewing pornographic } \\
\text { pictures or films }\end{array}$ & & $.35^{* *}$ & $.34 * *$ & $.30 * *$ \\
\hline
\end{tabular}

Note. s-IAT-sex $=$ short version of the Internet Addiction Test adapted to online sexual activities.

$* * p<.01 . * p<.05$. 
THE S-IAT-SEX: VALIDATION AND LINKS WITH ONLINE SEXUAL PREFERENCES AND ADDICTION SYMPTOMS

\section{References}

Albright, J. M. (2008). Sex in America online: An exploration of sex, marital status, and sexual identity in Internet sex seeking and its impacts. Journal of Sex Research, 45, 175186. doi: $10.1080 / 00224490801987481$

Ballester-Arnal, R. , Castro-Calvo, J., Gil-Llario, M. D. , \& Giménez-García, C. (2014). Relationship status as an influence on cybersex activity: Cybersex, youth, and steady partner. Journal of Sex and Marital Therapy, 40, 444-456. doi: $10.1080 / 0092623 X .2013 .772549$

Barke, A. , Nyenhuis, N. , \& Kröner-Herwig, B. (2012). The German version of the Internet Addiction Test: A validation study. CyberPsychology, Behavior, and Social Networking, 15, 534-542. doi: 10.1089/cyber.2011.0616

Billieux, J., Thorens, G. , Khazaal, Y., Zullino, D. , Achab, S. , \& Van der Linden, M. (2015). Problematic involvement in online games: A cluster analytic approach. Computers in Human Behavior, 43, 242-250. doi: 10.1016/j.chb.2014.10.055

Black, D. W. , Kehrberg, L. L. , Flumerfelt, D. L. , \& Schlosser, S. S. (1997). Characteristics of 36 subjects reporting compulsive sexual behavior. American Journal of Psychiatry, 154, 243-249. doi: 10.1176/ajp.154.2.243

Block, J. J. (2008). Issues for DSM-V: Internet addiction. American Journal of Psychiatry, 165, 306-307. doi: 10.1176/appi.ajp.2007.07101556

Brand, M. , Laier, C. , Pawlikowski, M. , Schachtle, U., Scholer, T. , \& Altstotter-Gleich, C. (2011). Watching pornographic pictures on the Internet: Role of sexual arousal ratings and psychological-psychiatric symptoms for using Internet sex sites excessively. Cyberpsychology Behavior \& Social Networking, 14, 371-377. doi: 10.1089/cyber.2010.0222 
Brown, T. (2006). Confirmatory factor analysis for applied research. New York, NY: Guilford Press.

Byrne, B. M. (1994). Structural equation modeling with EQS and EQS/Windows. Thousand Oaks, CA: Sage.

Carnes, P. (2000). Sexual addiction and compulsion: Recognition, treatment and recovery. CNS Spectrum, 5, 1-16.

Carnes, P. J. , Green, B. A. , Merlo, L. J. , Polles, A. , Carnes, S. , \& Gold, M. S. (2012). PATHOS: A brief screening application for assessing sexual addiction. Journal of Addiction Medicine, 6, 29-34. doi: 10.1097/ADM.0b013e3182251a28

Chan, P. A., \& Rabinowitz, T. (2006). A cross-sectional analysis of video games and attention deficit hyperactivity disorder symptoms in adolescents. Annals of General Psychiatry, 5, 16-26. doi: 10.1186/1744-859X-5-16

Chang, M. K. , \& Law, S. P. M. (2008). Factor structure for Young's Internet Addiction Test: A confirmatory study. Computers in Human Behavior, 24, 2597-2619. doi: 10.1016/j.chb.2008.03.001

Cohen, J. (1988). Statistical power analysis for the behavioral sciences. Hillsdale, NJ: Erlbaum.

Cooper, A. (1998). Sexuality and the Internet: Surfing into the new millenium. CyberPsychology and Behavior, 1, 181-187. doi: 10.1089/cpb.1998.1.187

Cooper, A. , Delmonico, D. L. , Griffin-Shelley, E. , \& Mathy, R. M. (2004). Online sexual activity: An examination of potentially problematic behaviors. Sexual Addiction \& Compulsivity, 11, 129-143. doi: 10.1080/10720160490882642 
Cooper, A. , Griffin-Shelley, E. , Delmonico, D. , \& Mathy, R. (2001). Online sexual problems: Assessment and predictive variables. Sexual Addiction \& Compulsivity, 8 , 267-285. doi: 10.1080/107201601753459964

Cooper, A., Månsson, S. A., Daneback, K. , Tikkanen, R. , \& Ross, M. W. (2003). Predicting the future of Internet sex: Online sexual activities in Sweden. Sexual and Relationship Therapy, 18, 277-291. doi: 10.1080/1468199031000153919

Cooper, A. , Morahan-Martin, J. , Mathy, R. M. , \& Maheu, M. (2002). Toward an increased understanding of user demographics in online sexual activities. Journal of Sexual Marital Therapy, 28, 105-129. doi: 10.1080/00926230252851861

Daneback, K. , Ross, M. W. , \& Månsson, S. A. (2006). Characteristics and behaviors of sexual compulsives who use the Internet for sexual purposes. Sexual Addiction \& Compulsivity, 13, 53-67. doi: 10.1080/10720160500529276

Faraci, P. , Craparo, G. , Messina, R. , \& Severino, S. (2013). Internet Addiction Test (IAT): Which is the best factorial solution? Journal of Medical Internet Research, 15, e225. doi: 10.2196/jmir.2935

Green, B. A. , Carnes, S. , Carnes, P. J. , \& Weinman, E. A. (2012). Cybersex addiction patterns in a clinical sample of homosexual, heterosexual, and bisexual men and women. Sexual Addiction \& Compulsivity, 19, 77-98.doi: 10.1080/10720162.2012.658343

Griffiths, M. D. (2012). Internet sex addiction: A review of empirical research. Addiction Research \& Theory, 20, 111-124. doi:10.3109/16066359.2011.588351

Griffiths, M. D. , King, D. L. , \& Demetrovics, Z. (2014). DSM-5 Internet gaming disorder needs a unified approach to assessment. Neuropsychiatry, 4, 1-4. doi: 10.2217/npy.13.82

Grov, C. , Gillespie, B. J. , Royce, T. , \& Lever, J. (2011). Perceived consequences of casual online sexual activities on heterosexual relationships: A U.S. online survey. Archives of 
THE S-IAT-SEX: VALIDATION AND LINKS WITH ONLINE SEXUAL PREFERENCES AND

ADDICTION SYMPTOMS

Sexual Behavior, 40, 429-439. doi: 10.1007/s10508-010-9598-z

Jelenchick, L. A. , Becker, T. , \& Moreno, M. A. (2012). Assessing the psychometric properties of the Internet Addiction Test (IAT) in US college students. Psychiatry Research 196, 296-301. doi: 10.1016/j.psychres.2011.09.007

Jöreskog, K. G. , \& Sörbom, D. (1996). LISREL 8 user’s reference guide. Uppsala, Sweden: Scientific Software International.

Karila, L. , Wéry, A. , Weinstein, A. , Cottencin, O. , Petit, A. , Reynaud, M. , \& Billieux, J. (2014). Sexual addiction or hypersexual disorder: Different terms for the same problem? A review of the literature. Current Pharmaceutical Design, 20, 4012-4020. doi: $10.2174 / 13816128113199990619$

Khazaal, Y., Billieux, J., Thorens, G. , Khan, R. , Louati, Y., Scarlatti, E. , Theintz, F. , Lederrey, J. , Van Der Linden, M. , \& Zullino, D. (2008). French validation of the Internet Addiction Test. CyberPsychology and Behavior, 11, 703-706. doi: 10.1089/cpb.2007.0249

Khazaal, Y., van Singer, M. , Chatton, A. , Achab, S. , Zullino, D. , Rothen, S. , Khan, R. , Billieux, J. , \& Thorens, G. (2014). Does self-selection affect sample's representativeness in online surveys? An investigation in online video games research. Journal of Medical Internet Research, 17, e164. doi: 10.2196/jmir.2759

Korkeila, J. , Kaarlas, S. , Jääskeläinen, M. , Vahlberg, T. , \& Taiminen, T. (2010). Attached to the web: Harmful use of the Internet and its correlates. European Psychiatry, 25, 236241. doi: 10.1016/j.eurpsy.2009.02.008

Kuss, D. J. , Griffiths, M. D. , Karila, L. , \& Billieux, J. (2014). Internet addiction: A literature review of epidemiological research for the last decade. Current Pharmaceutical Design, 20, 4026-4052. doi: 10.2174/13816128113199990617 
Laier, C. , \& Brand, M. (2014). Empirical evidence and theoretical considerations on factors contributing to cybersex addiction from a cognitive-behavioral view. Sexual Addiction \& Compulsivity, 21, 305-321.doi: 10.1080/10720162.2014.970722

Laier, C. , Pawlikowski, M. , Pekal, J. , Schulte, F. P. , \& Brand, M. (2013). Cybersex addiction: Experienced sexual arousal when watching pornography and not real-life sexual contacts makes the difference. Journal of Behavioral Addictions, 2, 100-107.doi: 10.1556/JBA.2.2013.002

Laier, C. , Pekal, J. , \& Brand, M. (2014). Cybersex addiction in heterosexual female users of Internet pornography can be explained by gratification hypothesis. Cyberpsychology, Behavior, and Social Networking, 17, 505-511. doi: 10.1089/cyber.2013.0396

Pawlikowski, M. , Altstötter-Gleich, C. , \& Brand, M. (2013). Validation and psychometric properties of a short version of Young's Internet Addiction Test. Computers in Human Behavior, 29, 1212-1223. doi:10.1016/j.chb.2012.10.014

Pawlikowski, M. , \& Brand, M. (2011). Excessive Internet gaming and decision making: Do excessive World of Warcraft-players have problems in decision making under risky conditions? Psychiatry Research, 188, 428-433. doi: 10.1016/j.psychres.2011.05.017

Philaretou, A. G. , Ma lhfouz, A. Y. , \& Allen, K. R. (2005). Use of Internet pornography and men's well-being. International Journal of Men's Health, 4, 149-169. doi: 10.3149/jmh.0402.149

Ross, M. W. , Månsson, S. A. , \& Daneback, K. (2012). Prevalence, severity, and correlates of problematic sexual Internet use in Swedish men and women. Archives of Sexual Behavior, 41, 459-466. doi: 10.1007/s10508-011-9762-0

Smith, G. T. , McCarthy, D. M. , Anderson, K. G. (2000). On the sins of short-form development. Psychological Assessment, 12, 102-111. doi: 10.1037/1040-3590.12.1.102 
THE S-IAT-SEX: VALIDATION AND LINKS WITH ONLINE SEXUAL PREFERENCES AND

ADDICTION SYMPTOMS

Starcevic, V. (2013). Is Internet addiction a useful concept? Australian and New Zealand Journal of Psychiatry, 47, 16-19. doi: 10.1177/0004867412461693

Watters, C. A. , Keefer, C. V. , Kloosterman, P. H. , Summerfeldt, L. J. , \& Parker, J. (2013). Examining the structure of the Internet Addiction Test in adolescents: A bifactor approach. Computers in Human Behavior, 29, 2294-2302. doi:

10.1016/j.chb.2013.05.020

Wéry, A. , Karila, L. , De Sutter, P. , \& Billieux, J. (2014). Conceptualisation, évaluation et traitement de la dépendance cybersexuelle: Une revue de la littérature [Conceptualisation, assessment, and treatment of cybersexual addiction : A review]. Canadian Psychology, 55, 266-281. doi: 10.1037/a0038103

Wetterneck, C. , Burgess, A., Short, M. , Smith, A. , \& Cervantes, M. (2012). The role of sexual compulsivity, impulsivity, and experiential avoidance in Internet pornography use. The Psychological Record, 62, 3-18.

Widyanto, L. , \& McMurran, M. (2004). The psychometric properties of the Internet Addiction Test. CyberPsychology and Behavior, 7, 443-450. doi:10.1089/cpb.2004.7.443

Young, K. S. (1998). Caught in the net: How to recognize the signs of Internet addictionAnd a winning strategy for recovery. New York, NY: Wiley.

Young, K. S. , Pistner, M. , O’Mara, J. , \& Buchanan, J. (1999). Cyber-disorders: The mental health concern for the new millennium. CyberPsychology and Behavior, 2, 475-479. doi: 10.1089/cpb.1999.2.475 


\section{Appendix A}

French Version of the Short IAT-Sex (12 items)

Vous trouverez ci-dessous une liste de questions. Veuillez lire attentivement chaque question et y répondre le plus précisément possible. Veuillez choisir une seule réponse et vous assurer de répondre à toutes les questions. Il n'y a pas de bonnes ou de mauvaises réponses; il est donc important que vous y répondiez le plus honnêtement possible pour vous.

\begin{tabular}{cccccccccc}
\hline 1 & 2 & 3 & 4 & 5 & & & & \\
\hline Jamais & Rarement & Occasionnellement & Souvent & Toujours & & & & \\
& & & & & 1 & 2 & 3 & 4 & 5 \\
\hline
\end{tabular}

1. Vous arrive-t-il de rester sur des sites sexuels en ligne plus longtemps que vous en aviez l'intention au départ?

2. Vous arrive-t-il de négliger vos tâches quotidiennes afin de passer plus de temps sur des sites sexuels en ligne?

3. Arrive-t-il que vos notes/devoirs scolaires et/ou votre travail souffre(nt) du temps que vous passez sur des sites sexuels en ligne?

4. Vous arrive-t-il d'être sur la défensive ou de refuser de répondre si quelqu'un vous demande ce que vous faites sur des sites sexuels en ligne?

5. Vous arrive-t-il de répondre sur un ton brusque, de crier ou de vous montrer agacé si quelqu'un vous dérange pendant que vous êtes sur des sites sexuels en ligne?

6. Vous arrive-t-il de manquer de sommeil parce que vous êtes resté tard sur des sites sexuels en ligne?

7. Lorsque vous n'êtes pas sur des sites sexuels en ligne, vous arrive-t-il d'y penser activement ou de rêver d'y être ?

8 . Vous arrive-t-il de vous dire "juste encore quelques minutes" lorsque vous êtes sur des sites sexuels en ligne?

9. Vous arrive-t-il d'essayer de diminuer le temps que vous passez sur des sites sexuels en ligne sans y arriver?

10. Vous arrive-t-il de cacher aux autres le temps que vous passez en ligne sur des sites sexuels?

11. Vous arrive-t-il de choisir de passer plus de temps sur des sites sexuels en ligne plutôt que de sortir avec vos proches?

12. Vous arrive-t-il de vous sentir déprimé, de mauvaise humeur, ou énervé lorsque vous n'êtes pas sur des sites sexuels en ligne, puis de vous sentir mieux lorsque vous y êtes? 


\section{Appendix B}

English Version of the Short IAT-Sex (12 items)

Below you will find a list of questions. Please read each question carefully and answer them to the best of your ability. Only choose one response and please be sure to answer every question. There are no right or wrong answers; it is important that you rate the questions as honestly as possible.

\begin{tabular}{cccccccccc}
\hline 1 & 2 & 3 & 4 & 5 & & & & \\
\hline Never & Rarely & Sometimes & Often & Always & & & & \\
& & & & & 1 & 2 & 3 & 4 & 5 \\
\hline
\end{tabular}

1. How often do you find that you stay on Internet sex sites longer than you intended?

2. How often do you neglect household chores to spend more time on Internet sex sites?

3. How often do your grades/school work and/or your work suffer because of the amount of time you spend on Internet sex sites?

4. How often do you become defensive or secretive when anyone asks you what you do on Internet sex sites?

5. How often do you snap, yell, or act annoyed if someone bothers you while you are on Internet sex sites?

6. How often do you lose sleep due to being on Internet sex sites late at night?

7. How often do you feel preoccupied with online sexual activities when offline, or fantasize about being on Internet sex sites?

8. How often do you find yourself saying "just a few more minutes" when you are on Internet sex sites?

9. How often do you try to cut down the amount of time you spend on Internet sex sites and fail?

10. How often do you try to hide how long you have been on Internet sex sites?

11. How often do you choose to spend more time on Internet sex sites over going out with others?

12. How often do you feel depressed, moody or nervous when you are offline, which goes away once you are back on Internet sex sites? 